Volume 8. No. 10, October 2020

International Journal of Emerging Trends in Engineering Research

Available Online at http://www.warse.org/IJETER/static/pdf/file/ijeter758102020.pdf

https://doi.org/10.30534/ijeter/2020/758102020

\title{
Investigation of the Possibility of using Suspended Polyvinyl Chloride and Ethylene-vinyl Acetate Copolymer to Produce a Thermoplastic Polymer Composition
}

\author{
Sayfullo Musaev ${ }^{1}$, Gulnoz Samieva ${ }^{2}$, Zuhriddin Majidov $^{3}$ \\ ${ }^{1}$ Dean of the Faculty "Textile and Leather Industry", associate professor of Bukhara Engineering Technological \\ Institute, Bukhara, Uzbekistan. Email: master64511@gmail.com \\ ${ }^{2} \mathrm{PhD}$ student of Bukhara Engineering Technological Institute, Bukhara, Uzbekistan. \\ ${ }^{3}$ Assistant Department of Technological Machines and Equipment, Bukhara Engineering Technological Institute, \\ Bukhara, Uzbekistan.
}

\begin{abstract}
The article explores the possibilities of using domestic suspension polyvinyl chloride and ethylene-vinyl acetate copolymer to obtain materials for the bottom of footwear for special purposes for operation in dry and hot climates. The grades of suspension polyvinyl chloride and the amount of plasticizer were determined. The influence of the amount of plasticizer on the physicomechanical properties of the thermoplastic polymer sole composition was investigated. Also, the work investigated the influence of the brand and the amount of ethylene-vinyl acetate copolymer on operational, technological and other properties. The concentration range of domestically produced suspension polyvinyl chloride n-copolymer of ethylene with vinyl acetate from 95: 5 to 55:45 was investigated. The choice of the range of permissible ratios of the mixture components was carried out and the permissible range of variation of the mixture compositions was obtained.

The values of indicators of consumer properties of a thermoplastic polymer composition based on PVC / EVA are compared with the corresponding indicators of other TPEs, it is determined that thermoplastic elastomers have similar values of indicators. It has been proved that thermoplastic polymer compositions based on PVC / EVA, possessing practically unlimited possibilities in terms of varying the composition and technological parameters of displacement, manufacturers have the ability to obtain, in each specific case, materials with the necessary complex of consumer and technological properties.
\end{abstract}

Key words: Suspension polyvinyl chloride, ethylene-vinyl acetate copolymer, formulation and technological parameters, thermoplastic elastomers, polymer sole composition, shoe sole materials.

\section{INTRODUCTION}

In the modern period, the acute problem of providing the population with consumer goods, in particular, footwear can be solved only on the basis of a radical technological re-equipment of enterprises in the leather and footwear industry through the use of the most effective solutions of domestic and world science and technology aimed at expanding the range of footwear materials, on increasing labor productivity.

The solution to many problems of the footwear industry has become possible only thanks to the creation of new polymer composite materials with a wide range of values of operational properties.

In recent years, great success has been achieved in the field of polymer formulation. Due to the development of chemistry and polymer technology, there is a tendency to gradually limit the use of the synthesis method as the main one in the creation of polymer materials. At the same time, the use of other methods of obtaining new materials is expanding, in particular, the modification of polymers with the aim of directed change in their properties. This provides not only chemical and structural modification, but also the creation of polymer - polymer and filled polymer compositions, as well as complex modification [1].

However, to date, there are no systematic studies on the methods of obtaining a thermoplastic polymer composition; there are no scientific approaches to managing the indicators of physical-mechanical and physical-chemical properties [2]. The question of the development of recipe and technological parameters for obtaining materials for the bottom of special-purpose footwear and revealing the influence of the composition of the composition on the operational, technological and other properties that determine the choice of the composite material and the area of use remains unstudied.

Based on this, the most promising direction for creating polymer - polymer systems is to obtain a polymer composition based on polymers with close cohesion energies $[3,4]$. 
Sayfullo Musaev et al., International Journal of Emerging Trends in Engineering Research, 8(10), October 2020, 7105 - 7110

\section{MATERIALS AND METHODS}

In this work, we investigated the possibility of using compositions based on domestic suspension polyvinyl chloride and ethylene-vinyl acetate copolymers with various vinyl acetate contents to obtain a thermoplastic polymer composition as the main binder for the production of shoe sole materials $[5,6]$.

Suspension polyvinyl chloride is a product of vinyl chloride polymerization by the suspension method.

$$
\left(-\mathrm{CH}_{2}-\mathrm{CHCl}-\right)_{n}
$$

Designed for the manufacture of products by extrusion, calendering, pressing, rolling and injection molding.

The domestic industry produces three grades of suspension polyvinyl chloride: PVC-S - 4700, PVC-S - 6346M, PVC-S 6346Zh, the main characteristics of which shown in Table 1.

Table 1: Main characteristics of suspension PVC of various grades

\begin{tabular}{|c|l|c|c|c|}
\hline \multirow{2}{*}{ № } & \multicolumn{1}{|c|}{ Indicators } & \multicolumn{2}{c|}{ PVC-S grades } \\
\cline { 3 - 4 } & & $\mathbf{4 7 0 0}$ & $\mathbf{6 3 4 6 M}$ & $\mathbf{6 3 4 6 Z H}$ \\
\hline 1 & Viscosity, ml / g & $135-127$ & $118-107$ & $106-96$ \\
\hline 2 & Fickencher coefficient Kf & $72-71$ & $68-66$ & $65-63$ \\
\hline 3 & Medium polymerization & $1350-1250$ & $1135-981$ & $980-846$ \\
\hline 4 & Number of impurity particles, no more, pcs. & 30 & 30 & 30 \\
\hline 5 & Volatile matter content (including water), no more, \% & 0,40 & 0,40 & 0,40 \\
\hline 6 & Surface density, not less, g / ml & 0,42 & 0,42 & 0,45 \\
\hline 7 & Remains of the screen, 0.25 mm mesh, no more, $\%$ & 2,0 & 2,0 & 2,0 \\
\hline 8 & Remains of a screen, 0.063 mm mesh, no more, $\%$ & 90 & 90 & 90 \\
\hline 9 & The number of "fish eye" / 400 cm2, no more & 40 & 40 & 40 \\
\hline 10 & Absorption coefficient of plasticizer per 100 g of resin, not & 25 & 19 & 16 \\
\hline 11 & less, g & 75 & 75 & 75 \\
\hline 12 & Conite degree (1600C, after 10 min), not less, $\%$ & $5 \cdot 10^{-3}$ & ------ & ----- \\
\hline 13 & Residual vinyl chloride content, no more, ppm & 10 & 10 & 10 \\
\hline
\end{tabular}

$18 \%$ ), CEVA (VA - $29 \%$ ), the main characteristics of which

In this work, to modify the properties of the polymer-bottom composition, we used a copolymer of ethylene with vinyl are given in Table 2 . acetate with different contents of vinyl acetate: CEVA (VA -

Table 2: Main characteristics of ethylene-vinyl acetate copolymer

\begin{tabular}{|c|c|c|c|}
\hline № & The name of indicators & $\begin{array}{c}\text { SEVA } \\
(\mathrm{VA-18 \%})\end{array}$ & $\begin{array}{c}\text { SEVA } \\
(\mathrm{VA-29} \%)\end{array}$ \\
\hline 1 & Appearance & granules & granules \\
\hline 2 & GOST or TU & $11507-070$ & $11708-210$ \\
\hline 3 & Molecular weight, thous. & $30-500$ & $30-500$ \\
\hline 4 & Solubility parameters, $\left(\mathrm{cal} / \mathrm{cm}^{3}\right)^{1 / 2}$ & 9,4 & 9,4 \\
\hline 5 & Melt index (MFR), g / $10 \mathrm{~min}$ & $7-12$ & $15-27$ \\
\hline 6 & Density, $\mathrm{kg} / \mathrm{m}^{3}$ & 0,944 & 0,950 \\
\hline 7 & Tensile strength, MPa (not less) & 8,0 & 5,9 \\
\hline 8 & Elongation at break, $\%$ & $800-700$ & $600-500$ \\
\hline 9 & Residual elongation at break, $\%$ & Over 100 & Over 100 \\
\hline 10 & Vicat heat resistance, ${ }^{0} \mathrm{C}$ & 100 & 100 \\
\hline 11 & Shore hardness, conventional units & 85 & 76 \\
\hline 12 & Melting point, ${ }^{0} \mathrm{C}$ & 125 & 125 \\
\hline 13 & Adhesive strength, not less $(\mathrm{kgf} / \mathrm{cm})$ & 2,7 & 3,92 \\
\hline
\end{tabular}

To impart elasticity to PVC compositions, various plasticizers added, of which the most famous are esters of phthalic and phosphoric acids. The content of plasticizers in the PVC composition can vary within the range of $3-100 \%$, which significantly affects the physicochemical and hygienic properties of the material $[7,8]$. Of the plasticizers, dioctyl 
phthalate (DOP) was preferred. The choice of these polymers as the main object of research is due to a complex of valuable properties, the possibility of obtaining a thermoplastic polymer sole composition based on them by the "dynamic vulcanization" method and processing into a product on high-performance injection molding units, a stable raw material base and a relatively low cost of these polymers [9]. To assess the qualitative and quantitative indicators of the properties of polymer sole compositions at various stages of the experiment, standard and original research methods were used with the use of modern equipment and devices.

Ultimate strength, relative and residual elongation at break were determined according to GOST 7762-84 on an Instron-1022 tensile testing machine.

Shore A hardness of the obtained polymer sole composition was determined according to GOST 24621-2015 on an analog Shore durometer mounted on a tripod with a loading device. The density of the obtained samples was determined according to GOST 15139-84 [10,11].

Polymer sole compositions based on mixtures of polymers were obtained by mechanical mixing under certain conditions in the mixing chamber of a plasticorder manufactured by Brabender (Germany) model PLV-651. Technical characteristics of plastic order:

Loading volume $60-600 \mathrm{~cm}^{3}$

Front rotor speed $20-180 \mathrm{rpm}$

The temperature of the mixing chamber is $18-300{ }^{\circ} \mathrm{C}$.

The plasticorder is equipped with a device for recording and recording the torque on the shaft.

The technological process and parameters of obtaining a thermoplastic polymer sole composition is the "know-how" of manufacturing firms, therefore, at the stage of an exploratory experiment, the technology for obtaining polymer mixtures was determined, which consists of the following operations:

1. Preparation of raw materials and ingredients.

1.1. Drying of polymers.

1.2. Grinding of caked ingredients.

2. Mixing of components.

2.1. The melting of suspension polyvinyl chloride was carried out in the mixing chamber of the plasticorder with constant intensive stirring at a temperature $10-40{ }^{\circ} \mathrm{C}$ higher than the melting temperature of the thermoplastic.

2.2. The mixing of the thermoplastic with a copolymer of ethylene with vinyl acetate was carried out in the mixing chamber of the plasticorder with constant intensive stirring for 2-6 minutes.

3. Cooling and granulation.

3.1. The resulting homogeneous thermoplastic elastomer mixture was cooled on cold rollers.

3.2. Granulation was carried out on a Marris granulator (Italy). As a result of granulation, granules of 2-4 $\mathrm{mm}$ in size were obtained.

4. Recycling. To increase the homogeneity of the polymer mixture, the composition was re-melted, cooled and granulated.

5. Samples for testing were obtained by pressing on vulcanizing presses and by casting on an automatic plating machine from Marris (Italy). The size of the test pieces is 250x130x8 mm.

\section{RESULTS AND DISCUSSION}

As mentioned above, the domestic industry produces 3 grades of suspension polyvinyl chloride with the trade name PVC-S-4700, PVC-S-6346-M, PVC-S-6346-Zh with different viscosity values. and the Fickencher coefficient. Providing in the future the injection method of manufacturing finished products, we will carry out a priori selection of research objects. In order to select the optimal brand of suspension polyvinyl chloride and the amount of plasticizer, an analysis was carried out. For each brand of suspension polyvinyl chloride, samples were obtained with different contents of dioctyl phthalate. In each specific case, the amount of plasticizer varied from 60-100 mass.h. per 100 mass.h. suspension polyvinyl chloride. The samples obtained for the study were monolithic, smooth plates with a dry to the touch on the surface $[12,13]$.

The study of the deformation and strength properties of the obtained samples was carried out according to the standard method on a tensile testing machine from the Instron-1022 company. The results obtained from the studies carried out to determine the ratio of PVC: DOP are presented in Fig. 1.

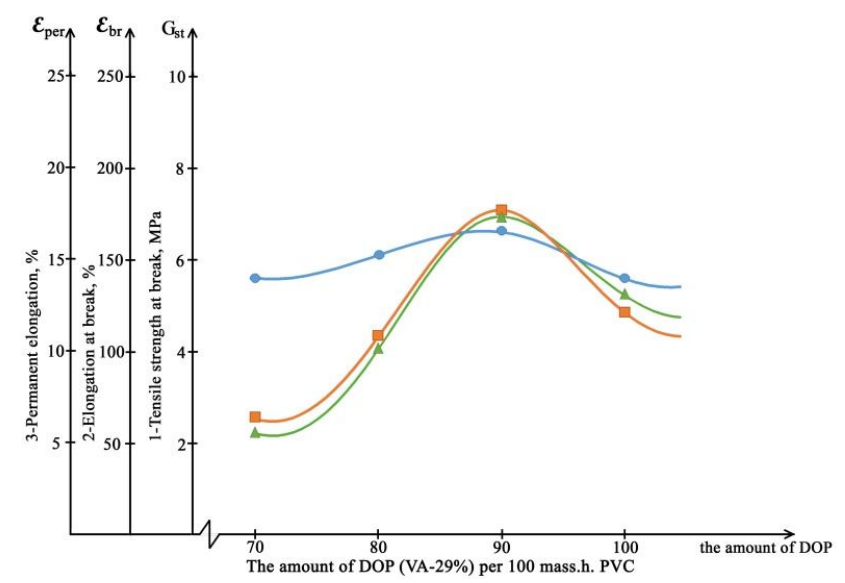

Figure 1: Dependence of indicators of physical and mechanical properties of samples on the ratio of PVC: DOP, 1-tensile strength; 2-elongation at break; 3-elongation at break; 4-hardness; 5-density.

As can be seen from the figure, when the content of dioctyl phthalate is from 60-90 mass.h. per 100 mass.h. suspension polyvinyl chloride tensile strength, elongation at break, permanent elongation at break, the density of the polymer composition increases, the hardness of the polymer composition decreases, and at a content of 100 mass.h. dioctyl 
phthalate per 100 wt.h. suspension polyvinyl chloride indicators of deformation and strength properties begins to fall. This indicates that when the content of the plasticizer is up to 90 mass.h. per 100 mass.h. of polyvinyl chloride in the studied brands, the dependence is proportional. That is, the plasticizer is well combined with polyvinyl chloride, forming a homogeneous mass. Therefore, based on the results of the experiment, for further research and modification of the properties of polyvinyl chloride, the optimal ratio is PVC: $\mathrm{DOP}=1: 09[14,15]$.

The values of the physical and mechanical properties of polymer sole compositions are influenced by both the brand of suspension polyvinyl chloride and the brand of ethylene-vinyl acetate copolymer.

The study investigated the concentration range of polyvinyl chloride suspension-copolymer of ethylene with vinyl acetate from 95: 5 to 55:45. Figures 2-3 show the curves of changes in ultimate strength at break, relative and residual elongation of samples of polymer sole compositions based on PVC-S-6346M and the following EVA grades: SEVA (VA $18 \%)$, SEVA (VA - $29 \%$ ).

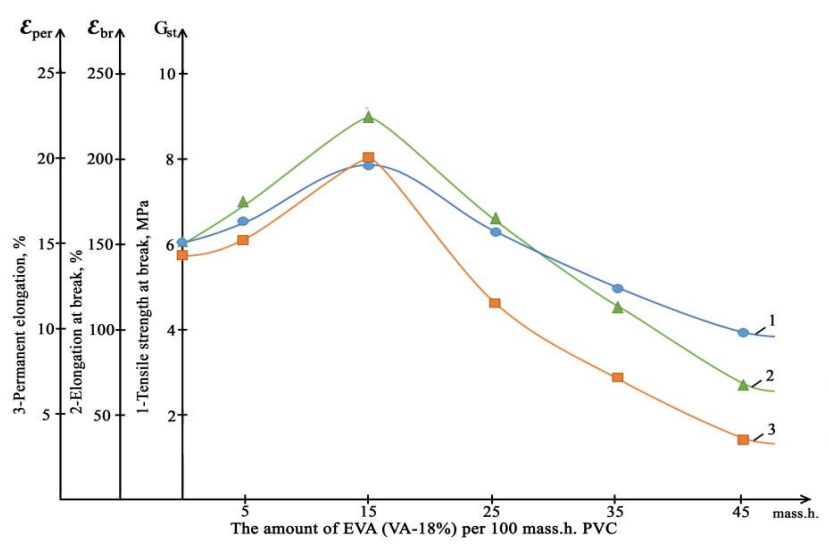

Figure 2: Curves of changes in deformation and strength properties PVC / EVA samples VA - $18 \%$, 1-tensile strength; 2-elongation at break; 3-elongation at break.

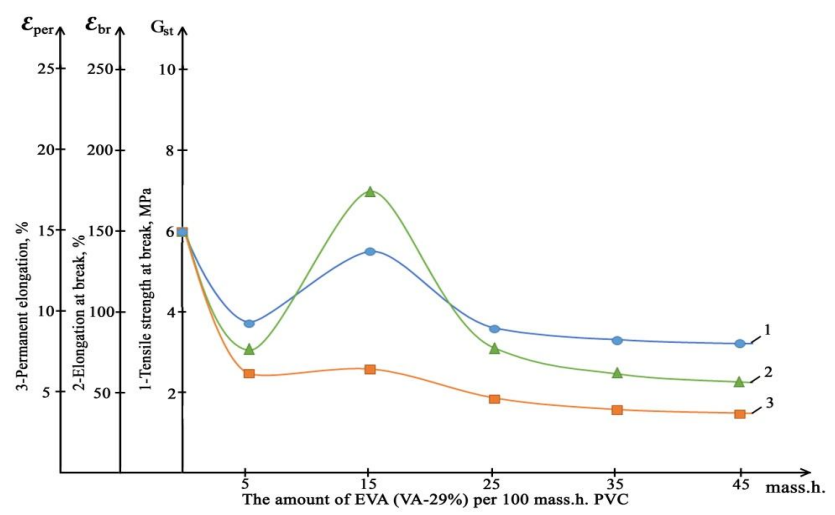

Figure 3: Curves of changes in deformation and strength properties PVC / EVA samples VA - 29\%, 1-tensile strength; 2-elongation at break; 3-elongation at break.
In the general case, with an increase in the content of the indicated CEVA grades, the values of the tensile strength at break, the relative and residual elongation increase to the ratio PVC: $\mathrm{CEVA}=85: 15$, and then these indicators decrease. However, it should be noted that the nature of these changes is greatly influenced by the CEVA brands. The values of the deformation and strength characteristics of the composition based on PVC / EVA (VA - $18 \%$ ) significantly exceed the content of VA - $29 \%$ from the CEVA grade. Moreover, the value of the ultimate strength at break, relative elongation and residual elongation increase sharply, especially in the area from 5 to 15 mass.h. SEVA in the composition, and the tensile strength at break of the composition PVC-S-6346M $/$ SEVA $($ VA $-18 \%)=85 / 15$ has a maximum value [16].

The influence of molecular weight on the tensile strength is easily explainable: the higher the molecular weight of PVC and EVA, the higher the strength characteristics. The parameter characterizing the molecular weight of $\mathrm{PVC}$ is the Fickencher number. It is more difficult to explain the differences between the values of the ultimate strength at break from the additive straight line. In our opinion, the difference in the strength values of the compositions is explained by the chemical composition of the polyvinyl chloride and the percentage of vinyl acetate groups in the ethylene-vinyl acetate copolymer. Since suspension PVC is characterized in a "pure" polymer by the presence of a relatively large amount of impurities remaining in the polymer after the polymerization process. Dispersants remaining in the PVC composition can play the role of combining agents when creating a PVC / EVA composition, which leads to an increase in the strength properties of such compositions [17].

Analysis of the curves of change in the deformation and strength properties of PVC / SEVA samples (Figure 2-3) shows that from the point of view of footwear production, the most acceptable composition is PVC-S-6346M / SEVA with a VA content of $18 \%$. This is also confirmed by the fact that the value of the relative elongation decreases most smoothly, without going beyond the limit corresponding to the lower value of consumer requirements, which is determined during the questionnaire. The value of the residual elongation corresponds to the requirements for shoe sole materials and has a tendency to a sharp decrease in comparison with the CEVA brand containing VA - $29 \%$.

Thus, the selection of the range of permissible ratios of the mixture components was carried out. For these purposes, the "property-composition indicators" graphs (Fig. 2-3) show the boundaries of the permissible property values. The admissible range of variation of mixture compositions was obtained: (wt. \%) PVC-S-6346M: SEVA (VA - 18\%) = 85: $15 \div 75: 25$; PVC-S-6346M: SEVA $(V A-29 \%)=85: 15 \div 75: 25$. 
A wide range of requirements are imposed on the polymer compositions used to obtain shoe sole materials [5]. Table 4 shows the values of the most significant quality indicators. Comparing the values of indicators of consumer properties of thermoplastic polymer compositions based on PVC / EVA with the corresponding indicators of other TPEs $[4,18,19]$, it is seen that thermoplastic elastomers have similar values of indicators. Moreover, having practically unlimited possibilities in terms of varying the composition and technological parameters of displacement, manufacturers have the ability to obtain in each case materials with the necessary complex of consumer and technological properties and they can be recommended as a base component for the production of shoe bottom parts operated in dry and dry conditions. hot climate.

Table 4: Values of the most significant quality indicators

\begin{tabular}{|c|c|c|c|c|c|c|c|}
\hline \multirow{2}{*}{ № } & \multirow{2}{*}{ The name of indicators } & \multirow{2}{*}{ Copolymer type } & \multicolumn{5}{|c|}{ The composition of the polymer composition (wt.\%) } \\
\hline & & & $95: 5$ & $85: 15$ & $75: 25$ & $65: 35$ & $55: 45$ \\
\hline \multirow[t]{2}{*}{1} & $\begin{array}{l}\text { Shore A hardness } \\
\text { conventional units }\end{array}$ & SEVA (VA-18\%) & 62 & 63 & 65 & 65 & 65 \\
\hline & & SEVA (VA-29\%) & 62 & 63 & 65 & 65 & 65 \\
\hline \multirow[t]{2}{*}{2} & Density, $\mathrm{g} / \mathrm{cm}^{3}$ & SEVA (VA-18\%) & 1.43 & 1.37 & 1.35 & 1.30 & 1.23 \\
\hline & & SEVA (VA-29\%) & 1.45 & 1.40 & 1.30 & 1.30 & 1.07 \\
\hline \multirow[t]{2}{*}{3} & $\begin{array}{l}\text { Abrasion resistance, } \\
\mathrm{J} / \mathrm{mm}^{3}\end{array}$ & SEVA (VA-18\%) & 7.2 & 9.8 & 11.5 & 12.4 & 13.2 \\
\hline & & SEVA (VA-29\%) & 7.0 & 9.5 & 10.8 & 12.3 & 13.0 \\
\hline \multirow[t]{2}{*}{4} & $\begin{array}{l}\text { Thermal conductivity, } \\
\text { W / m K }\end{array}$ & SEVA (VA-18\%) & 0.21 & 0.19 & 0.18 & 0.15 & 0.14 \\
\hline & & SEVA (VA-29\%) & 0.22 & 0.20 & 0.18 & 0.16 & 0.13 \\
\hline \multirow[t]{2}{*}{5} & Heat resistance, ${ }^{0} \mathrm{C}$ & SEVA (VA-18\%) & 115 & 110 & 104 & 97 & 94 \\
\hline & & SEVA (VA-29\%) & 112 & 105 & 98 & 95 & 92 \\
\hline
\end{tabular}

\section{CONCLUSIONS}

Thus, in the course of experimental studies, the nature of the change in the physicomechanical properties of polymer composites was revealed depending on the type and amount of ethylene-vinyl acetate copolymer.

It has been proved that polyvinyl chloride, which forms the basic structure of the polymer mixture, has the effect of changing the parameters of the physical and mechanical properties of the prevailing factors. The presence of extrema changes in the values of indicators of behavior on structural changes in the polymer matrix.

Considering that polymer compositions based on domestic suspension polyvinyl chloride and a copolymer of ethylene with vinyl acetate have a cost price that is half that of polyurethane, divinyl styrene TPEs. Polymer compositions based on domestic suspension polyvinyl chloride and a copolymer of ethylene with vinyl acetate should be recognized as promising materials for the production of shoe bottom parts operated in a dry hot climate.

\section{REFERENCES}

[1]. Polymer mixtures. Ed. J. Paul, S. Newman. Per. English. Moscow: Mir, 1981, vol. 1, p. 5, vol. 2, p. 39.

[2]. Wu E., Burlon J., Paul D. Compatible blends of vinyl chloride copolymer with vinylidene chloride with polymethyl acrylates. MalcolmDollSymp. Waco, Tex., 30 Apr. - 1 May, 1982., "I. Polym. Sci .: Polym. Symp. ”, 1984, No. 71, p. 137-150.

[3]. Guytord H. Compatibilizing agents: Structurt and function in polyblend. "I. Macromol. Sci. ", 1989, A 26, No. 8, p. 12, no. 1292 (England).

[4]. Wehnberry R. Thermoplasticselastomerics. "Plast. World", 1985, 43, №5, p. 30-34.

[5]. Musaev S.S., Samieva G.O. Determination of one indicators of the quality of shoe sources of the understanding materials, International Journal of Advanced Research in Science, Engineering and Technology Vol. 6, Issue 9, September 2019.

[6]. Deshmukh D. T. and Lunge H. S. Impact of Global Warming on Rainfall, And Cotton Lint With Vulnerability Profiles of Five Districts In Vidarbha, International Journal of Scientific \& Technology Research, vol. 1, is. 11, 2012. pp. 77-85.

[7]. Juraev Anvar and Rajabov Ozod. Analysis of the interaction of Fibrous Material with a Multifaceted Grid of the cleaner, International Journal of Recent Technology and Engineering, vol. 8, 1, 2019, pp. 2661-2666.

[8]. M. O. Wankhade and U. V. Kale. Multiple Regression Model For Optimization of Yield of Cotton In Rain Fed Zone of Maharashtra, International Journal of Scientific \& Technology Research, vol. 8, is. 12, 2019, pp. 208-211.

[9]. A. Juraev and O. Rajabov. Experimental study of the 
interaction of multifaceted and cylindrical spiky cylinder in cotton cleaner from small waste, International Journal of Advanced Research Science. Engineering and Technology, vol. 6, 3, 2019, pp. 8382-8387.

[10]. Ozod Rajabov, Ziyodullo Shodiyev, Ikrom Inoyatov, Mastura Gapparova. Analysis of the Technological Process of Cleaning Raw Cotton from Small Trash, International Journal of Emerging Trends in Engineering Research, Volume 8. No. 9, September 2020, pp. 6022-6029.

[11].O. I. Rajabov, A. S. Abrorov, N. I. Mirzaqulova, G. B. Zaripov and Kh. S. Ziyodullaev. An experimental study of the location of the grid bars cells installed under spiked cylinders in a cotton cleaner from small waste, IOP Conference Series: Materials Science and Engineering, 2020, 862032049.

[12]. Ozod Rajabov, Fazliddin Kurbonov, Mastura Gapparova and Shakhrillo Jumaev. The influence of the location of the cells on the allocation of weed impurities for cleaning raw cotton from fine waste, IOP Conference Series: Materials Science and Engineering, 2020, 862032027.

[13]. Akbar Abrorov, Matluba Kuvoncheva, Ozod Rajabov, Mukhsin Mukhammadov and Shakhrillo Jumaev. Method of thermal treatment of saw disk teeth of fiber- processing machines by laser quenching, IOP Conference Series: Materials Science and Engineering, 2020, 862032034.

[14].Z. Shodiyev, A. Shomurodov and O. Rajabov. The results of the experimental nature of the vibrations of the grid cotton cleaner, IOP Conference Series: Materials Science and Engineering, 2020, 883012169

[15]. Rajabov Ozod Isroilovich, The influence of the mode of movement of the pieces cotton when interacting with a cotton grid, International Journal of Advanced Research in Science, Engineering and Technology. Vol. 6, Issue 3, (2019), pp. 8455-8381.

[16]. Ozod Rajabov and Ziyodullo Shodiyev, Analysis of Small Fluctuations of a Multifaceted Mesh under the Influence of Technological Load from the Cleaned Cotton - Raw, International Journal of Advanced Research in Science, Engineering and Technology, Vol. 6, Issue 10, (2019), pp. 11396-11399.

[17]. Bekhruz Gaybulloev, Nigina Ergasheva, Ozod Rajabov, The Structure of the Embroidery Machine and Dynamic Analysis of the Needle Mechanism, International Journal of Advanced Research in Science, Engineering and Technology, Vol. 7, Issue 1, (2020), pp. 8376-8381.

[18].Smirnova Zhanna.V, Vaganova O.I., Chaykina Zh. V., Golubeva O.V. Calculation of metallurgical processes during welding, International Journal of Emerging Trends in Engineering Research, Volume 8. No. 5, May 2020, pp 1529-1534.

[19].A.M.Mahaboob Basha, M.Rajaiah, P.Penchalaiah, CH.Raja Kamal, B.Niranjana Rao. Machine Learning-Structural Equation Modeling Algorithm: The Moderating role of Loyalty on Customer Retention towards Online Shopping, International Journal of Emerging Trends in Engineering Research, Volume 8. No. 5, May 2020, pp. 1578-1585. 